\title{
Psychotic and nonpsychotic mood disorders in autoimmune encephalitis: diagnostic issues and research implications
}

\author{
Giuseppe Quaranta ${ }^{1}$, Nunzio Bucci ${ }^{2}$, Cristina Toni ${ }^{3}$, Giulio Perugi ${ }^{1,3}$ \\ ${ }^{1}$ Department of Experimental and Clinic Medicine, Section of Psychiatry, University of Pisa, 56100 Pisa, Italy. \\ ${ }^{2}$ Department of Mental Health, Health District, 74100 Taranto, Italy. \\ ${ }^{3}$ Institute of Behavioural Science, G.De Lisio, 56100 Pisa, Italy.
}

\section{A B S T R A C T}

Recent research on autoimmune disorders suggests additional links between systemic and central nervous system (CNS) pathophysiology, among which the identification of antibody-induced limbic encephalitis provided the strongest evidence for the potential involvement of autoimmunity in the pathogenesis of severe mood and psychotic symptoms. In these illnesses, psychiatric symptoms predominate in the initial phase of the disorder in up to $70 \%$ of the cases, and they often lead patients to early psychiatric evaluation. For this reason, it is very important to increase the limited knowledge among psychiatrists about these autoimmune neuropsychiatric diseases, which can mimic psychiatric syndromes, in particular, those typically presented in severe mood disorders and schizophrenia. On the other hand, similarities in clinical presentation suggest that neuroinflammation and systemic immune dysregulation may play a role in the pathophysiology of severe mood and psychotic disorders. A complex interaction between periphery and immune cells of the CNS may result in cellular damage through mechanisms involving excitotoxicity, oxidative stress, and mitochondrial dysfunction. These pathways are possibly shared between comorbid medical disorders and severe mood and psychotic disorders and may reflect common underlying vulnerability.

Key words: Autoimmune encephalitis, mood disorders, psychosis

\section{INTRODUCTION}

The connection between autoimmunity and neuropsychiatric symptoms has long been acknowledged, and William Osler provided a description of psychosis in systemic lupus erythematosus in 1895. The myasthenic syndromes are good examples of how autoantibodies can cause neurological symptoms. ${ }^{[1]}$ As another example, some paraneoplastic syndromes such as cerebellar degeneration or limbic encephalitis (LE) are associated with highly specific antibodies against intracellular neuronal proteins and aggressive cytotoxic T-cell responses that usually lead to irreversible deficits. ${ }^{[2]}$

Corresponding Author: Dr. Giulio Perugi, Department of Experimental and Clinic Medicine, Section of Psychiatry, University of Pisa, Via Roma 67, 56100 Pisa, Italy.

E-mail: giulio.perugi@med.unipi.it

\begin{tabular}{|l|l|}
\hline \multicolumn{2}{|c|}{ Access this article online } \\
\hline Quick Response Code: & \\
\hline & Website: \\
\cline { 2 - 3 } & Www.nnjournal.net \\
\hline
\end{tabular}

In recent times, the discovery of a range of autoantibodies acting on specific synaptic sites in the brain has been an important development for the identification of different forms autoimmune encephalitis, often characterized by the initial psychiatric presentation. The predominance of a psychopathological expression often leads patients to early psychiatric evaluation and treatment. ${ }^{[3]}$ As a result, in many cases, the correct diagnosis may be delayed because of the limited knowledge among psychiatrists about these autoimmune neuropsychiatric diseases mimicking psychiatric syndromes, in particular, severe mood disorders and schizophrenia. ${ }^{[4-6]}$ Moreover, the fact that a variety of neuropsychiatric disorders may initially present with

This is an open access article distributed under the terms of the Creative Commons Attribution-NonCommercial-ShareAlike 3.0 License, which allows others to remix, tweak, and build upon the work non-commercially, as long as the author is credited and the new creations are licensed under the identical terms. For reprints contact: nn_editor001@nnjournal.net

Cite this article as: Quaranta G, Bucci N, Toni C, Perugi G. Psychotic and nonpsychotic mood disorders in autoimmune encephalitis: diagnostic issues and research implications. Neuroimmunol Neuroinflammation 2015;2:228-36.

Received: 12-03-2015; Accepted: 13-04-2015 
psychiatric symptoms very similar to classical mood and psychotic disorders reinforced the hypothesis that innate inflammation/autoimmunity may be relevant to the pathogenesis of psychiatric symptoms at least in a subset of patients with bipolar disorder ${ }^{[7]}$ or schizophrenia. ${ }^{[8]}$

\section{AUTOIMMUNE ENCEPHALITIS}

Since 1974, Mitsuda and Fukuda ${ }^{[9]}$ described "atypical psychosis" as some acute and transient psychotic disorders, which cannot be easily classified as either schizophrenia or mood disorder with psychotic features. Some important clinical characteristics of atypical psychosis include acute onset, emotional and psychomotor disturbances, alternations of consciousness, high prevalence in women, and well-adjusted premorbid personality. In these conditions, an involvement of neurologic brain changes has been hypothesized.

The identification of autoimmune encephalitis, a new category of neuropsychiatric diseases that occurs with focal or widespread involvement of the nervous system in association with antibodies against extracellular epitopes of neuronal cell-surface or synaptic proteins, have led to changed paradigms for the diagnosis and treatment for some neuropsychiatric disorders, and reclassification of syndromes previously defined as idiopathic or with descriptive terms. ${ }^{[10]}$ Since 2005, there have been 1-2 discoveries of novel syndromes and associated autoantigens per year, including autoantigens the $N$-methyl-D-aspartate receptor (NMDAR) ${ }^{[11,12]}$ the subunits Kv1.1 and Kv1.2 of the voltage-gated potassium channels (VGKCs), the $\alpha$-amino-3-hydroxy-5-methyl-4-isoxazol-pro pionic acid receptor (AMPAR), ${ }^{[13]}$ metabotropic glutamate receptor $5,{ }^{[14]}$ or the $\gamma$-amino-butyric acid B-receptor (GABAbR), ${ }^{[15]}$ leucine-rich glioma inactivated 1 (Lgi1), ${ }^{[16]}$ contactin associated protein 2 (CASPR2). ${ }^{[17]}$ The study of these disorders has revealed novel mechanisms of how antibodies might alter memory, behavior, cognition and cause mood disorders, psychosis, seizures or abnormal movements. ${ }^{[18,19]}$ However, though obtaining serum to test for autoantibodies is extremely convenient and relatively noninvasive, the caveats of using serum antibodies as a diagnostic tool need to be considered. Neuronal surface antibodies are not $100 \%$ specific. ${ }^{[20-25]}$ In particular, lower serum titers should be interpreted with caution, and the role of evaluating cerebrospinal fluid (CSF) neuronal surface antibodies rather than serum titers may increase diagnostic specificity. ${ }^{[10]}$ The presence of neuronal surface antibodies should always be correlated with the clinical picture.
One important clinical feature of autoimmune encephalitis is the strong association between autoantibody production and the presence of teratoma or other neoplasms. Comorbidities of autoimmune encephalitis with small cell lung carcinoma, neuroblastoma, ovarian carcinoma, breast carcinoma, thymoma, and testicular cancers have also been reported. ${ }^{[26]}$ These findings suggested that the autoantibody syndrome may be triggered by cross-reaction between antibodies produced in response to tumor presence and antigenically similar synaptic proteins within the central nervous system (CNS). Autoimmune encephalitis can develop, however, with or without an underlying tumor, and in the largest case series to date, no teratoma or other type of tumor was detected in $41 \%$ of cases. ${ }^{[3,27]}$

Different forms of autoimmune encephalitis can affect patients of all ages although some of them seem to preferentially occur in late childhood and young adulthood. ${ }^{[28,29]}$ The onset of the symptomatology shows a substantial overlap among the different types. Sometimes associated with headache or mild hyperthermia, the initial clinical picture is characterized by a rapid development of a set of psychiatric and/ or neurological symptoms. Mood disorders, usually manic or mixed-manic symptoms, anxiety, behavioral problems, psychotic features, mild to moderate disorders of consciousness, and memory loss occur in most types of autoimmune encephalitis, often associated with seizures. Demographic information (such as gender and race), presence or absence of a underlying tumor, brain magnetic resonance imaging (MRI) findings, CSF examination, and the severity and predominance of some symptoms over others can suggest a specific subtype.

Ultimately, two approaches have been proposed for the diagnosis of autoimmune encephalitis: one based on the laboratory examination as proposed by Lancaster and Dalmau $^{[10]}$ and the other based on clinical diagnostic criteria as proposed by Zuliani et al. ${ }^{[30]}$ The latter recommend that one should suspect a diagnosis of an autoimmune encephalitis when a patient presents with acute or subacute onset of symptoms, evidence of inflammation supported by CSF examination, imaging, or histopathological investigations, and the exclusion of other infectious, metabolic, and toxic etiologies. Supportive criteria include a history of other autoimmune comorbidities, and preceding infectious prodromes. Using a combination of these criteria as well as test of response to therapy, they suggest a model whereby patients can be classified as having definite, probable or possible neuronal cell surface antibody related pathology. ${ }^{[30,31]}$ 


\section{Anti-NMDAR encephalitis}

Anti-NMDAR encephalitis, among all the autoimmune encephalitis, is the best-understood variant and the most frequently associated with almost exclusively psychiatric presentation. The illness was first described as a distinct clinical entity in an observational study in 2005 by Vitaliani et al. ${ }^{[11]}$ in four young women who developed acute psychiatric symptoms, seizures, memory deficits, decreased level of consciousness, autonomic instability, and hypoventilation in association with the presence of an ovarian teratoma. Two years later, a paper by this group described the underlying pathology, mediated by auto-antibodies directed against the NR1 subunit of the NMDAR. ${ }^{[12]}$ These antibodies cause a decrease in the number of NMDARs in target cells by inducing cross-linking and internalization of NMDARs by autophagy. ${ }^{[2]}$ Therefore, anti-NMDAR encephalitis represents a state of NMDA-R hypofunction, associated to glutamate dysregulation. ${ }^{[33]}$ Initially, it was classified as a paraneoplastic syndrome ${ }^{[12]}$ due to the strong association (upwards of 60\%) with a teratoma or other tumor types.

Although many patients have been diagnosed with anti-NMDAR encephalitis to date, the exact prevalence of this disorder is unknown. A study of 100 patients revealed that although most patients are young women, the disorder can occur in men and children. ${ }^{[34]}$ In fact, with increasing awareness of the syndrome, the number of pediatric cases has steadily grown and appears to represent about $40 \%$ of all cases. ${ }^{[28]}$ The younger the patient, the less likely an underlying tumor will be detected at the time of presentation. ${ }^{[34]}$

A stereotypical clinical course with different phases is noted for patients with anti-NMDAR encephalitis. ${ }^{[35]}$ In $70 \%$ of patients, the illness begins with a prodromal phase lasting 5-14 days. ${ }^{[3,36]}$ This nonspecific flu-like prodrome is characterized by subfebrile temperature, fatigue, malaise, headache, nausea, diarrhea, vomiting. This is followed by other clinical phases, which may vary in sequence, presentation and severity.

After the initial phase, psychiatric manifestations go on to develop, including emotional and behavioral disturbances such as apathy, anxiety, panic attacks, fear, depression, decreased cognitive skills, sleep disorders. In most cases, an excited manic or mixed manic symptomatology develops in a variable lapse of time, from hours to days; mood disorders and agitation are almost invariably associated with psychotic features such as grandiose delusions, Capgras syndrome, paranoid interpretation, and different types of hallucinations. From mild to moderate cognitive disorders are frequently presented. ${ }^{[18,37]}$ During this phase, patients are often referred to psychiatric assessment and may receive treatment with psychoactive agents or admission to psychiatric facilities.

This psychotic phase can be followed by physical decompensation involving autonomic instability (less common in children), with hypo- or hypertension, hypo- or hyperthermia, hypoventilation, cardiac arrhythmia, decreased responsiveness, and occasionally short-term memory loss. Some patients may also have seizures, most commonly generalized tonic-clonic, but also partial and/or complex type. In some patients, early treatment with antiepileptic drugs may mask seizures. Dyskinesias, extrapyramidal signs, and stereotyped motor automatisms may also be observed. ${ }^{[38]}$ During this phase, patients not already admitted to the hospital often present to the emergency department because they no longer follow verbal commands and may appear mute (with language disintegration) and akinetic. Patients may maintain gaze as if in a catatonic state, smile inappropriately, or demonstrate stereotyped athetosic movements. ${ }^{[34,39]}$

Since the initial descriptions, further studies have expanded the clinical phenotype of this syndrome. Some patients with anti-NMDAR antibodies have predominant or isolated psychiatric features, dystonia, or epilepsy, without the classic multistage presentation, potentially representing a forme fruste of anti-NMDAR encephalitis, mimicking a psychiatric disorder. ${ }^{[3,40]}$

The diagnosis of anti-NMDAR encephalitis is confirmed by the detection in serum or CSF of antibodies to the NR1 subunit of the NMDA receptor. After treatment or in advanced stages of the disease, the CSF antibodies usually remain elevated if there is no clinical improvement, whereas serum antibodies may be substantially decreased by treatments. The titer of CSF antibodies appears to correlate more closely with the clinical outcome. Patients with anti-NMDAR encephalitis may have abnormalities of both CSF and MRI. 80\% of patients with confirmed anti-NMDAR encephalitis have abnormal CSF with the majority of them exhibiting a lymphocytic pleocytosis, but over a half also show raised proteins. There may also be the presence of isolated oligoclonal bands in the CSF of patients with autoimmune encephalitis (around $60 \%) .{ }^{[3]}$ In contrast to the consistency of the clinical picture, MRI findings are less predictable; only 55\% of patients had increased fluid-attenuated inversion recovery (FLAIR) or T2 signal in one or several brain regions, without significant correlation with patients' symptoms. MRI can be normal or demonstrate medial temporal involvement or focal areas of hyperintensity in the frontal or parietal cortex. Other studies demonstrated that [18F]-fluorodeoxyglucose positron emission 
tomography can show cortical hypermetabolism in acute stages and hypometabolism in more subacute stages of the illness. ${ }^{[5,41]}$ In over three-quarters of patients, EEG shows generalized or frontotemporal slow or disorganized activity without epileptic discharges. ${ }^{[28]}$ These findings may overlap with electrographic seizures.

\section{Other autoimmune encephalitis}

This group of autoimmune diseases can be defined as LE. LE was first described in the 1960s in patients with severe short-term memory impairment or dementia in association with bronchial carcinoma. ${ }^{[42]}$ Cardinal symptoms of LE are severe short-term memory impairment with psychiatric symptoms such as personality change, depression, anxiety, hallucinations, confusion, and complex partial-often temporal or classically in LGI1 encephalitis facio-brachial tonic seizures $^{[43]}$ and generalized seizures. ${ }^{[44]}$ Another prominent symptom found in $40 \%$ of patients and also exhibited in mice lacking LGI1, ${ }^{[16]}$ is myoclonus.

\section{Anti-AMPAR encephalitis}

AMPAR antibodies (Glutamate receptors - GluR1/2) can be one of the autoimmune causes of LE. Glutamate is one of the main excitatory neurotransmitters with GluR1/2 being the predominant AMPA subtype in the hippocampus (GluR3 is associated with the distinct disorder, Rasmussen's syndrome). About $70 \%$ of patients have an underlying tumor in the lung, breast or thymus. ${ }^{[13,45]}$ These patients develop acute limbic dysfunction that can be associated with prominent psychiatric symptoms. Most patients, commonly middle-aged women, present with the subacute onset of disorientation, confusion, memory loss, and aggressive behavior. CSF findings and brain MRI are similar to those of anti-NMDAR encephalitis. The long-term prognosis depends on the controlling of the tumor and presence of coexisting symptoms related to onconeuronal antibodies.

\section{Anti- $\gamma$-amino-butyric acid beta encephalitis}

This encephalitis is caused by disruption of the metabotropic GABAbR, and equally affects both sexes. These patients present with LE, prominent seizures, and memory dysfunction. ${ }^{[46]}$ About half of the patients had an associated tumor, either a small cell lung cancer (SCLC) or a neuroendocrine tumor of the lung. ${ }^{[15]}$ The MRI and CSF findings are similar to those in other types of LE, with unilateral or bilateral increases in medial temporal lobe FLAIR or T2 signal consistent with LE and CSF lymphocytic pleocytosis.

\section{Anti-LGI1 encephalitis}

Although previously termed anti-voltage-gated potassium channel encephalitis (anti-VGKC encephalitis), recent evidence suggests that actually other autoantigens (LGI1 and CASPR2) are associated with this LE.

Antibody-mediated mutation and disrupted function of LGI1 (a secreted neuronal protein that interacts with presynaptic and postsynaptic receptors) have been associated with the syndrome of autosomal dominant lateral temporal lobe epilepsy, ${ }^{[5,47]}$ and have been shown to cause increased excitability, which may result in memory disturbances, confusion and seizures, with MRI findings that are usually typical of LE. LGI1 antibodies have been most recently associated with adult-onset brief, but frequent motor events which comprise unilateral upper limb jerking and ipsilateral facial grimacing, termed "faciobrachial dystonic seizures". ${ }^{[43]}$ Some patients develop hyponatremia (60\%) or REM sleep-behavior disorders. Only $11 \%$ of cases are associated with a neoplasm, most commonly thymoma or SCLC. ${ }^{[16]}$ In those who do have a tumor, the encephalitis can precede the identification of the neoplasm in up to three-quarters of patients. ${ }^{[48,49]}$

\section{Anti-CASPR2 encephalitis}

Contactin associated protein 2 is an axonal protein of the neurexin IV superfamily. Mutations in the human gene encoding CASPR2 have been associated with autism, epilepsy, obsessive-compulsive disorders, and Tourette syndrome. ${ }^{[10]}$ These patients usually develop symptoms of encephalitis, drug-refractory epilepsy, peripheral nerve hyperexcitability, or both (Morvan's syndrome or neuromyotonia). ${ }^{[17,50]}$ CNS symptoms include cognitive impairment, memory loss, hallucinations, and seizures.

\section{MOOD AND PSYCHOTIC SYMPTOMS IN AUTOIMMUNE ENCEPHALITIS}

Depending on the clinical presentation and the timing of evaluation, the psychiatric manifestations of autoimmune encephalitis can be diagnosed following DSM 5 criteria as mood disorder with psychotic and or catatonic features due to a general medical condition (GMC), but also as psychotic disorder or delirium due to GMC, where the GMC is autoimmune encephalitis. In many patients, there is no previous personal or family history of psychiatric disorders. The psychiatric presentation looks like a delirious mania or acute confusional state that develops over a short period of time, fluctuates over the course of the day and manifests with changes in cognition, affect, behavior, and perception. Initially, the features may be subtle, but over days to weeks, there may be dramatic worsening, culminating in an unresponsive and catatonic state..$^{[51]}$

Patients may present labile mood, with a wide range of emotions including anxiety, low or euphoric mood, 
irritability, apathy or changes in behavior including agitation/restlessness alternating with episodes of somnolence.

A case of anti-NMDAR encephalitis mimicking bipolar disorder has been described.. ${ }^{[52]}$ More recently Steiner et al. ${ }^{[53]}$ examined patients with schizophrenia $(n=121)$, major depressive disorder $(n=70)$, and borderline personality disorder $(n=38)$ and found that $9.9 \%$ of the patients diagnosed with schizophrenia had NMDAR-R antibodies in their serum compared with $2.8 \%$ of the depressed patients and $0 \%$ of the borderline personality disorder. Interestingly, patients with schizophrenia, who were seropositive, had immunoglobulin $\mathrm{G}$ antibodies not only directed against the NR1a subunit of the NMDAR but also against the NR1a/NR2b subunit again raising the question about the level of involvement the immune system might have in the pathogenesis of some forms of psychotic disorders.

Perceptual disturbances are also common, including misinterpretations, illusions or hallucinations (visual and auditory) and delusions (often pertaining to hallucinations). During the unresponsive phase, patients have been referred to as catatonic with features involving purposeless motor activity, extreme negativism, bizarre posturing, grimacing, mutism, echolalia, and echopraxia.

It has been hypothesized that in a proportion of patients diagnosed as bipolar or psychotic disorders, autoantibodies may be present during an earlier developmental period resulting in a gradual and chronic exposure to NMDA-R hypofunction. ${ }^{[54]}$ Because of the similarities in symptom presentation, the possible role of autoimmunity in bipolar- and psychotic-spectrum disorders seems to represent a promising direction for future research.

\section{AUTOIMMUNE DISEASES AND PSYCHOTIC AND NON PSYCHOTIC MOOD DISORDERS}

Many evidences suggest a role of inflammatory mediators and immune dysregulations in the pathogenesis of psychiatric disorders such as $\mathrm{BD},{ }^{[7,55,56]}$ schizophrenia, ${ }^{[8]}$ depression, ${ }^{[57]}$ and Alzheimer's disease. ${ }^{[58]}$

Autoimmune diseases, as well as BD and schizophrenia, are multifactorial disorders related to an interaction between gene and environment. ${ }^{[59]} \mathrm{A}$ familial occurrence is commonly found..$^{[60]}$ Moreover, autoimmune reactions often advance much more slowly than immune reactions to pathogens, suggesting that control mechanisms can continue to work until a threshold has been exceeded leading to a progression from subclinical to clinically significant symptomatology as in mood and psychotic disorders. In addition, in autoimmune diseases, the mechanisms of control may temporarily restore the antigenic tolerance, leading to a cyclical pattern of exacerbation and remission of the disease. These general pathophysiological mechanisms of autoimmunity lead to common clinical features, including familial occurrence, progression from subclinical to the clinical level of the symptomatology, and the exacerbation-remission periodic course. Interestingly, both affective and nonaffective psychosis have been definitively shown to possess all these clinical features.

In a recent study by our group, ${ }^{[61]}$ on a clinical sample of $347 \mathrm{BD}$ patients, we found a very high prevalence (48.1\%) of AAD. The result is particularly interesting for two reasons: first, for the disproportion with the prevalence observed in the general population (in our country the estimated prevalence in general population is about $3.2 \%$ for autoimmune diseases and about $20-30 \%$ for allergic conditions): ${ }^{[62,63]}$ second, for the lack of a difference in gender distribution, because AAD are usually more represented in women.

The association between $\mathrm{AAD}$ and $\mathrm{BD}$ has rarely been systematically investigated in clinical samples. An increased prevalence of mood symptoms has been found in a variety of inflammatory conditions, including auto-immune diseases, cardiovascular diseases, diabetes, obesity, and metabolic syndrome, as well as in more benign inflammatory conditions such as asthma and allergies. ${ }^{[64]} \mathrm{A}$ large Danish cohort study showed that a history of Guillain-Barre syndrome, Crohn's disease, and autoimmune hepatitis was associated with raised risk of BD. ${ }^{[56]}$ The authors concluded that autoimmune processes precede the onset of BD. A subsequent study, based on Danish hospital data, reported that a broad range of autoimmune diseases and infections requiring hospitalization increase the risk of developing schizophrenia and mood disorders. ${ }^{[65]}$ The observed associations support a possible immunological contribution in subgroups of patients with severe mental disorders, such as bipolar and other psychotic disorders. However, whether it is a causal relationship or an epiphenomenon due to other environmental factors or common genetic vulnerability remains to be clarified and deserve further research. Genetically vulnerable individuals might be at a particular risk of developing mood disorders as a consequence of autoimmune reactions and inflammation affecting the brain.

Inflammatory mechanisms can affect the brain through many different pathways that are not necessarily mutually exclusive. ${ }^{[66-68]}$ Peripheral inflammation can affect the brain without passing the blood-CNS 
barrier by proinflammatory cytokines activating the tryptophan-kynurenine pathway, regulating serotonin production together with NMDA and glutamate receptor activity and may also indirectly affect dopamine regulation. ${ }^{[69]}$ The increased inflammation in autoimmune diseases may also influence the brain through increased permeability of the blood-CNS barriers, making the brain vulnerable to immune components, such as cytokines and auto-antibodies. Furthermore, brain-reactive antibodies can induce a range of psychiatric and neurological symptoms, as observed in association with antibody-induced LE. ${ }^{[12]}$

More controversial and less explored by the literature is the association we found between AAD comorbidity, generalized anxiety, and cyclothymic-anxious temperament. ${ }^{[61]}$ This finding suggests a possible intriguing relationship between autoimmune-mediated inflammatory process, trait emotional reactivity, and stress vulnerability.

Although the link between stress and mood disorders is well-recognized, ${ }^{[70]}$ there are no specific studies examining the role of stress, immune dysregulation, and autoimmunity in BD. Retrospective studies in autoimmune diseases have found that up to $80 \%$ of patients report uncommon emotional stress before disease onset, ${ }^{[71]}$ and it has been suggested that immune system activation may vary across affective states in BD patients. ${ }^{[72]}$ In a more theoretical perspective, it is possible to hypothesize a "constitutional" reinforcing loop between emotional/mood reactivity and autoimmune/allergic reactivity that characterizes the "usual" self of these individuals and influence the entire span of their existence.

Interestingly, in our sample, the lifetime prevalence of cancer and neoplastic diseases was very low, involving less than $1 \%$ of the patients. Recent data suggested an association between certain diagnosis and a lower-than-expected probability (negative comorbidity) of developing other disorders. ${ }^{[73]}$ It has been recently suggested that the immune system and other regulatory systems, particularly, the peripheral nervous system, convey signals from tumor cells to the brain that might play a part in tumor progression and metastases, through sympathetic and parasympathetic nerves, and by the modulation of the hypothalamic-pituitary-adrenal axis and adrenal medulla activity. ${ }^{[74]}$ The majority of studies have focused on cancer and schizophrenia; ${ }^{[75]}$ there are few data regarding patients with $\mathrm{BD} \cdot{ }^{[76]}$ Although individuals with Schizophrenia and BD are exposed to more environmental noxious agents that contribute to tumor development (e.g. tobacco and alcohol) than the general population, results of several population-based studies indicate that patients with schizophrenia have a lower risk of prostate, colorectal cancers, and melanoma but a higher risk of breast and lung cancer. The increased risk for certain tumors could be associated with diverse and non mutually exclusive factors such as drug side-effects, unhealthy lifestyle, poor access to health care and differences in socioeconomic status. On the other hand, the reduced risk of other types of cancer may be explained by genetic factors, such as the increased expression of various candidate tumor suppressor genes, or the decreased expression of some oncogenes in genomic regions implicated in schizophrenia or $\mathrm{BD}$ susceptibility. ${ }^{[77,78]}$ An alternative explanation may be related to the possibility of an increased immune reactivity in patients with BD and/or other mental disorders. ${ }^{[7]}$ During the process of carcinogenesis, in fact, naturally occurring antibody responses to tumor antigens were found to be associated with improved survival and protection against the spread of cancer. ${ }^{[79]}$ In recent trials, on cancer immunotherapy, clinically significant antitumor responses were often associated with the induction of autoimmune toxicity. ${ }^{[80]}$ This finding suggests that the same immune mechanisms that elicit autoimmunity may also contribute to the destruction of tumors.

\section{CONCLUSION}

Neuroinflammation and peripheral immune dysregulation may play a role in the pathophysiology of severe mood and psychotic disorders. Recent research on autoimmune disorders provides additional links between systemic and CNS pathophysiology. ${ }^{[7]}$ This involves a complex interaction between immune cells of the CNS and periphery resulting in cellular damage through mechanisms involving excitotoxicity, oxidative stress, and mitochondrial dysfunction. ${ }^{[7]}$ These pathways are possibly shared between comorbid medical disorders and severe mood and psychotic disorders and may reflect common underlying vulnerabilities.

Some of the strongest evidence for the potential of autoimmunity and immune components to cause psychiatric symptoms comes from the identification of antibody-induced LE, where psychiatric symptoms are often dominant in the initial and the remission phase of the disorder in up to $70 \%$ of the cases, ${ }^{[12,34]}$ and which has been demonstrated to be treatable with immune therapies. ${ }^{[81]}$ The prevalently psychiatric presentation of some of these autoimmune limbic encephalitis often leads patients to early psychiatric evaluation. For this reason, it is very important to increase the 
limited knowledge among psychiatrists about these autoimmune neuropsychiatric diseases mimicking psychiatric syndromes, in particular, severe mood disorders and schizophrenia.

\section{Financial support and sponsorship}

Nil.

\section{Conflicts of interest}

There are no conflicts of interest.

\section{REFERENCES}

1. Titulaer MJ, Lang B, Verschuuren JJ. Lambert-Eaton myasthenic syndrome: from clinical characteristics to therapeutic strategies. Lancet Neurol 2011;10:1098-107.

2. Darnell RB, Posner JB. Paraneoplastic syndromes involving the nervous system. N Engl J Med 2003;349:1543-54.

3. Dalmau J, Lancaster E, Martinez-Hernandez E, Rosenfeld MR, Balice-Gordon R. Clinical experience and laboratory investigations in patients with anti-NMDAR encephalitis. Lancet Neurol 2011:10:63-74.

4. Davison K. Autoimmunity in psychiatry. $B r J$ Psychiatry 2012;200:353-5.

5. Rosenfeld MR, Dalmau J. Anti-NMDA-receptor encephalitis and other synaptic autoimmune disorders. Curr Treat Options Neurol 2011;13:324-32.

6. Sansing LH, Tuzun E, Ko MW, Baccon J, Lynch DR, Dalmau J. A patient with encephalitis associated with NMDA receptor antibodies. Nat Clin Pract Neurol 2007:3:291-6.

7. Rege S, Hodgkinson SJ. Immune dysregulation and autoimmunity in bipolar disorder: synthesis of the evidence and its clinical application. Aust N Z J Psychiatry 2013;47:1136-51.

8. Fan X, Goff DC, Henderson DC. Inflammation and schizophrenia. Expert Rev Neurother 2007;7:789-96.

9. Mitsuda H, Fukuda T, editors. Biological Mechanisms of Schizophrenia and Schizophrenia-like Psychoses. Tokio: Igaku Shoin; 1974.

10. Lancaster E, Dalmau J. Neuronal autoantigens-Pathogenesis, associated disorders and antibody testing. Nat Rev Neurol 2012;8:380-90.

11. Vitaliani R, Mason W, Ances B, Zwerdling T, Jiang Z, Dalmau J. Paraneoplastic encephalitis, psychiatric symptoms, and hypoventilation in ovarian teratoma. Ann Neurol 2005;58:594-604.

12. Dalmau J, Tuzun E, Wu HY, Masjuan J, Rossi JE, Voloschin A, Baehring JM, Shimazaki H, Koide R, King D, Mason W, Sansing LH, Dichter MA, Rosenfeld MR, Lynch DR. Paraneoplastic anti-N-methyl-D-aspartate receptor encephalitis associated with ovarian teratoma. Ann Neurol 2007:61:25-36.

13. Lai M, Hughes EG, Peng X, Zhou L, Gleichman AJ, Shu H, Mata S, Kremens D, Vitaliani R, Geschwind MD, Bataller L, Kalb RG, Davis R, Graus F, Lynch DR, Balice-Gordon R, Dalmau J. AMPA receptor antibodies in limbic encephalitis alter synaptic receptor location. Ann Neurol 2009;65:424-34.

14. Lancaster E, Martinez-Hernandez E, Titulaer MJ, Boulos M, Weaver S, Antoine JC, Liebers E, Kornblum C, Bien CG, Honnorat J, Wong S, Xu J, Contractor A, Balice-Gordon R, Dalmau J. Antibodies to metabotropic glutamate receptor 5 in the Ophelia syndrome. Neurology 2011;77:1698-701.

15. Lancaster E, Lai M, Peng X, Hughes E, Constantinescu R, Raizer J, Friedman D, Skeen MB, Grisold W, Kimura A, Ohta K, lizuka T, Guzman M, Graus F, Moss SJ, Balice-Gordon R, Dalmau J. Antibodies to the GABA(B) receptor in limbic encephalitis with seizures: case series and characterisation of the antigen. Lancet Neurol 2010;9:67-76.
16. Lai M, Huijbers MG, Lancaster E, Graus F, Bataller L, Balice-Gordon R, Cowell JK, Dalmau J. Investigation of LGI1 as the antigen in limbic encephalitis previously attributed to potassium channels: a case series. Lancet Neurol 2010;9:776-85.

17. Lancaster E, Huijbers MG, Bar V, Boronat A, Wong A, Martinez-Hernandez E, Wilson C, Jacobs D, Lai M, Walker RW, Graus F, Bataller L, Illa I, Markx S, Strauss KA, Peles E, Scherer SS, Dalmau J. Investigations of caspr2, an autoantigen of encephalitis and neuromyotonia. Ann Neurol 2011;69:303-11.

18. Moscato EH, Jain A, Peng X, Hughes EG, Dalmau J, Balice-Gordon RJ. Mechanisms underlying autoimmune synaptic encephalitis leading to disorders of memory, behavior and cognition: insights from molecular, cellular and synaptic studies. Eur JNeurosci 2010:32:298-309.

19. Panzer JA, Gleichman AJ, Lynch DR. Glutamatergic autoencephalitides: an emerging field. $J$ Neural Transm 2014;121:957-68.

20. Uzawa A, Mori M, Takahashi Y, Ogawa Y, Uchiyama T, Kuwabara S. Anti-N-methyl D-aspartate-type glutamate receptor antibody-positive limbic encephalitis in a patient with multiple sclerosis. Clin Neurol Neurosurg 2012;114:402-4.

21. Fujita K, Yuasa T, Takahashi Y, Tanaka K, Sako W, Koizumi H, Iwasaki Y, Yoshida M, Izumi Y, Kaji R. Antibodies to N-methyl-D-aspartate glutamate receptors in Creutzfeldt-Jakob disease patients. J Neuroimmunol 2012;251:90-3

22. Kruer MC, Koch TK, Bourdette DN, Chabas D, Waubant E, Mueller S, Moscarello MA, Dalmau J, Woltjer RL, Adamus G. NMDA receptor encephalitis mimicking seronegative neuromyelitis optica. Neurology 2010;74:1473-5.

23. Nwosu VK, Royer JA, Stickler DE. Voltage gated potassium channel antibodies in amyotrophic lateral sclerosis. Amyotroph Lateral Scler 2010;11:392-4

24. Tuzun E, Kurtuncu M, Lang B, Icoz S, Akman-Demir G, Eraksoy M, Vincent A. Bickerstaff's encephalitis and Miller Fisher syndrome associated with voltage-gated potassium channel and novel anti-neuronal antibodies. Eur J Neurol 2010;17:1304-7.

25. Lin JJ, Lin KL, Hsia SH, Wang HS, Chiu CH, Group CS. VGKC complex antibodies in pediatric severe acute encephalitis: a study and literature review. Brain Dev 2013;35:630-5.

26. Titulaer MJ, Soffietti R, Dalmau J, Gilhus NE, Giometto B, Graus F Grisold W, Honnorat J, Sillevis Smitt PA, Tanasescu R, Vedeler CA, Voltz R, Verschuuren JJ, European Federation of Neurological S. Screening for tumours in paraneoplastic syndromes: report of an EFNS task force. Eur J Neurol 2011;18:19-e3.

27. Dalmau J, Rosenfeld MR. Paraneoplastic syndromes of the CNS Lancet Neurol 2008;7:327-40.

28. Florance NR, Davis RL, Lam C, Szperka C, Zhou L, Ahmad S, Campen CJ, Moss H, Peter N, Gleichman AJ, Glaser CA, Lynch DR, Rosenfeld MR, Dalmau J. Anti-N-methyl-D-aspartate receptor (NMDAR) encephalitis in children and adolescents. Ann Neurol 2009;66:11-8.

29. Armangue T, Petit-Pedrol M, Dalmau J. Autoimmune encephalitis in children. J Child Neurol 2012;27:1460-9.

30. Zuliani L, Graus F, Giometto B, Bien C, Vincent A. Central nervous system neuronal surface antibody associated syndromes: review and guidelines for recognition. $J$ Neurol Neurosurg Psychiatry 2012;83:638-45.

31. Suleiman J, Brilot F, Lang B, Vincent A, Dale RC. Autoimmune epilepsy in children: case series and proposed guidelines for identification. Epilepsia 2013;54:1036-45.

32. Hughes EG, Peng X, Gleichman AJ, Lai M, Zhou L, Tsou R, Parsons TD, Lynch DR, Dalmau J, Balice-Gordon RJ. Cellular and synaptic mechanisms of anti-NMDA receptor encephalitis. J Neurosci 2010;30:5866-75

33. Coyle JT, Tsai G. NMDA receptor function, neuroplasticity, and the pathophysiology of schizophrenia. Int Rev Neurobiol 2004:59:491-515.

34. Dalmau J, Gleichman AJ, Hughes EG, Rossi JE, Peng X Lai M, Dessain SK, Rosenfeld MR, Balice-Gordon R, Lynch DR. 
Anti-NMDA-receptor encephalitis: case series and analysis of the effects of antibodies. Lancet Neurol 2008;7:1091-8.

35. Wandinger KP, Saschenbrecker S, Stoecker W, Dalmau J. Anti-NMDA-receptor encephalitis: a severe, multistage, treatable disorder presenting with psychosis. $J$ Neuroimmunol 2011;231:86-91.

36. Luca N, Daengsuwan T, Dalmau J, Jones K, deVeber G, Kobayashi J, Laxer RM, Benseler SM. Anti-N-methyl-D-aspartate receptor encephalitis: a newly recognized inflammatory brain disease in children. Arthritis Rheum 2011;63:2516-22.

37. Pruss H, Dalmau J, Harms L, Holtje M, Ahnert-Hilger G, Borowski K, Stoecker W, Wandinger KP. Retrospective analysis of NMDA receptor antibodies in encephalitis of unknown origin. Neurology 2010;75:1735-9.

38. Barry H, Hardiman O, Healy DG, Keogan M, Moroney J, Molnar PP, Cotter DR, Murphy KC. Anti-NMDA receptor encephalitis: an important differential diagnosis in psychosis. $\mathrm{Br} J$ Psychiatry 2011;199:508-9.

39. Fawcett RG. Acute psychosis associated with anti-NMDA-receptor antibodies and bilateral ovarian teratomas: a case report. $J$ Clin Psychiatry 2010;71:504.

40. Reid DK, Clardy SL. Neurological picture. Anti-NMDA-receptor encephalitis: unusual presentation of an uncommon condition. J Neurol Neurosurg Psychiatry 2013;84:69-70.

41. Pillai SC, Gill D, Webster R, Howman-Giles R, Dale RC. Cortical hypometabolism demonstrated by PET in relapsing NMDA receptor encephalitis. Pediatr Neurol 2010;43:217-20.

42. Corsellis JA, Goldberg GJ, Norton AR. "Limbic encephalitis" and its association with carcinoma. Brain 1968;91:481-96.

43. Irani SR, Michell AW, Lang B, Pettingill P, Waters P, Johnson MR, Schott JM, Armstrong RJ, Zagami AS, Bleasel A, Somerville ER, Smith SM, Vincent A. Faciobrachial dystonic seizures precede Lgi1 antibody limbic encephalitis. Ann Neurol 2011;69:892-900.

44. Lawn ND, Westmoreland BF, Kiely MJ, Lennon VA, Vernino S. Clinical, magnetic resonance imaging, and electroencephalographic findings in paraneoplastic limbic encephalitis. Mayo Clin Proc 2003;78:1363-8.

45. Irani S, Lang B. Autoantibody-mediated disorders of the central nervous system. Autoimmunity 2008:41:55-65.

46. Prosser HM, Gill CH, Hirst WD, Grau E, Robbins M, Calver A, Soffin EM, Farmer CE, Lanneau C, Gray J, Schenck E, Warmerdam BS, Clapham C, Reavill C, Rogers DC, Stean T, Upton N, Humphreys K, Randall A, Geppert M, Davies CH, Pangalos MN. Epileptogenesis and enhanced prepulse inhibition in GABA (B1)-deficient mice. Mol Cell Neurosci 2001;17:1059-70.

47. Kawamata J, Ikeda A, Fujita Y, Usui K, Shimohama S, Takahashi R. Mutations in LGI1 gene in Japanese families with autosomal dominant lateral temporal lobe epilepsy: the first report from Asian families. Epilepsia 2010;51:690-3.

48. Gultekin SH, Rosenfeld MR, Voltz R, Eichen J, Posner JB, Dalmau J. Paraneoplastic limbic encephalitis: neurological symptoms, immunological findings and tumour association in 50 patients. Brain 2000;123 (Pt 7):1481-94

49. DanielSE, LoveS,ScaravilliF,HardingAE. Encephalomyeloneuropathy in the absence of a detectable neoplasm. Clinical and postmortem findings in three cases. Acta Neuropathol 1985;66:311-7.

50. Barber PA, Anderson NE, Vincent A. Morvan's syndrome associated with voltage-gated $\mathrm{K}+$ channel antibodies. Neurology 2000;54:771-2.

51. Peery HE, Day GS, Dunn S, Fritzler MJ, Pruss H, De Souza C, Doja A, Mossman K, Resch L, Xia C, Sakic B, Belbeck L, Foster WG. Anti-NMDA receptor encephalitis. The disorder, the diagnosis and the immunobiology. Autoimmun Rev 2012;11:863-72.

52. Choe CU, Karamatskos E, Schattling B, Leypoldt F, Liuzzi G, Gerloff C, Friese MA, Mulert C. A clinical and neurobiological case of IgM NMDA receptor antibody associated encephalitis mimicking bipolar disorder. Psychiatry Res 2013;208:194-6.

53. Steiner J, Walter M, Glanz W, Sarnyai Z, Bernstein HG, Vielhaber S, Kastner A, Skalej M, Jordan W, Schiltz K,
Klingbeil C, Wandinger KP, Bogerts B, Stoecker W. Increased prevalence of diverse $\mathrm{N}$-methyl-D-aspartate glutamate receptor antibodies in patients with an initial diagnosis of schizophrenia: specific relevance of IgG NR1a antibodies for distinction from $\mathrm{N}$-methyl-D-aspartate glutamate receptor encephalitis. JAMA Psychiatry 2013;70:271-8.

54. Maneta E, Garcia G. Psychiatric manifestations of anti-NMDA receptor encephalitis: neurobiological underpinnings and differential diagnostic implications. Psychosomatics 2014;55:37-44.

55. Berk M, Kapczinski F, Andreazza AC, Dean OM, Giorlando F, Maes M, Yucel M, Gama CS, Dodd S, Dean B, Magalhaes PV, Amminger P, McGorry P, Malhi GS. Pathways underlying neuroprogression in bipolar disorder: focus on inflammation, oxidative stress and neurotrophic factors. Neurosci Biobehav Rev 2011;35:804-17.

56. Eaton WW, Pedersen MG, Nielsen PR, Mortensen PB. Autoimmune diseases, bipolar disorder, and non-affective psychosis. Bipolar Disord 2010;12:638-46.

57. Krishnadas R, Cavanagh J. Depression: an inflammatory illness? $J$ Neurol Neurosurg Psychiatry 2012;83:495-502.

58. Holmes C, Cunningham C, Zotova E, Woolford J, Dean C, Kerr S, Culliford D, Perry VH. Systemic inflammation and disease progression in Alzheimer disease. Neurology 2009;73:768-74.

59. Ellis JA, Kemp AS, Ponsonby AL. Gene-environment interaction in autoimmune disease. Expert Rev Mol Med 2014;16:e4.

60. Cho JH, Gregersen PK. Genomics and the multifactorial nature of human autoimmune disease. N Engl J Med 2011;365:1612-23.

61. Perugi G, Quaranta G, Belletti S, Casalini F, Mosti N, Toni C, DellOsso L. General medical conditions in 347 bipolar disorder patients: clinical correlates of metabolic and autoimmune-allergic diseases. J Affect Disord 2015;170C:95-103.

62. Jacobson DL, Gange SJ, Rose NR, Graham NM. Epidemiology and estimated population burden of selected autoimmune diseases in the United States. Clin Immunol Immunopathol 1997;84:223-43

63. de Monchy JG, Demoly P, Akdis CA, Cardona V, Papadopoulos NG Schmid-Grendelmeier P, Gayraud J. Allergology in Europe, the blueprint. Allergy 2013;68:1211-8

64. Brydon L, Walker C, Wawrzyniak A, Whitehead D, Okamura H, Yajima J, Tsuda A, Steptoe A. Synergistic effects of psychological and immune stressors on inflammatory cytokine and sickness responses in humans. Brain Behav Immun 2009;23:217-24.

65. Benros ME, Nielsen PR, Nordentoft M, Eaton WW, Dalton SO Mortensen PB. Autoimmune diseases and severe infections as risk factors for schizophrenia: a 30-year population-based register study. Am J Psychiatry 2011;168:1303-10.

66. Eaton WW, Byrne M, Ewald H, Mors O, Chen CY, Agerbo E, Mortensen PB. Association of schizophrenia and autoimmune diseases: linkage of Danish national registers. Am J Psychiatry 2006;163:521-8.

67. Dalman C, Allebeck P, Gunnell D, Harrison G, Kristensson K, Lewis G, Lofving S, Rasmussen F, Wicks S, Karlsson H. Infections in the CNS during childhood and the risk of subsequent psychotic illness: a cohort study of more than one million Swedish subjects. Am J Psychiatry 2008;165:59-65.

68. Yolken RH, Torrey EF. Are some cases of psychosis caused by microbial agents? A review of the evidence. Mol Psychiatry 2008;13:470-9.

69. Dantzer R, O'Connor JC, Freund GG, Johnson RW, Kelley KW From inflammation to sickness and depression: when the immune system subjugates the brain. Nat Rev Neurosci 2008;9:46-56.

70. Weiss JM, Stout JC, Aaron MF, Quan N, Owens MJ, Butler PD, Nemeroff CB. Depression and anxiety: role of the locus coeruleus and corticotropin-releasing factor. Brain Res Bull 1994;35:561-72

71. Stojanovich L, Marisavljevich D. Stress as a trigger of autoimmune disease. Autoimmun Rev 2008;7:209-13.

72. Ortiz-Dominguez A, Hernandez ME, Berlanga C, Gutierrez-Mora D Moreno J, Heinze G, Pavon L. Immune variations in bipolar 
disorder: phasic differences. Bipolar Disord 2007;9:596-602.

73. Tabares-Seisdedos R, Rubenstein JL. Inverse cancer comorbidity: a serendipitous opportunity to gain insight into CNS disorders. Nat Rev Neurosci 2013;14:293-304.

74. Ondicova K, Mravec B. Role of nervous system in cancer aetiopathogenesis. Lancet Oncol 2010;11:596-601.

75. Kredentser MS, Martens PJ, Chochinov HM, Prior HJ. Cause and rate of death in people with schizophrenia across the lifespan: a population-based study in Manitoba, Canada. J Clin Psychiatry 2014;75:154-61.

76. Crump C, Sundquist K, Winkleby MA, Sundquist J. Comorbidities and mortality in bipolar disorder: a Swedish national cohort study. JAMA Psychiatry 2013;70:931-9.
77. Beaulieu JM. A role for Akt and glycogen synthase kinase-3 as integrators of dopamine and serotonin neurotransmission in mental health. J Psychiatry Neurosci 2012;37:7-16.

78. Zheng W, Wang H, Zeng Z, Lin J, Little PJ, Srivastava LK, Quirion R. The possible role of the Akt signaling pathway in schizophrenia. Brain Res 2012;1470:145-58.

79. Toubi E, Shoenfeld Y. Protective autoimmunity in cancer (review). Oncol Rep 2007;17:245-51.

80. Toomer KH, Chen Z. Autoimmunity as a double agent in tumor killing and cancer promotion. Front Immunol 2014;5:116.

81. Graus F, Saiz A, Dalmau J. Antibodies and neuronal autoimmune disorders of the CNS. J Neurol 2010;257:509-17. 